\title{
Comparative study of labetalol and nifedipine in management of hypertensive disorders of pregnancy in BRIMS tertiary care center
}

\author{
Uma B Deshmukh, Savitha A, Sangeeta Tengli \\ Corresponding author: Dr. Savitha A, C/O Navjeevan Hospital, Beside Church, Behind Hotel \\ Mayura, Opposite New Central Bus Stand, Vijay Nagar, Bidar, Karnataka, India; \\ Email : drsavitha96@rediffmail.com
}

Distributed under Attribution-Non Commercial - Share Alike 4.0 International (CC BY-NC-SA 4.0)

\section{ABSTRACT}

\begin{abstract}
Objective: To compare the efficacy and safety of oral labetalol and nifedipine in hypertensive disorder of pregnancy. Methods: A prospective comparative study was carried out in obstetrics and gynaecology department BRIMS tertiary care center between June 2019 to December 2019. This study included 60 antenatal women irrespective of parity and gestational age from 20-40 weeks with hypertensive disorder. Chronic hypertension, diabetes, cardiac, renal disease, hemophilia and bronchial asthma were excluded from the study. The efficacy of labetalol and nifedipine were compared. Results: In this study fall in systolic blood pressure (SBP), diastolic blood pressure (DBP) and mean arterial pressure (MAP) in labetalol group was statistically significant when compared to nifedipine. Outcome of fetus was also better with use of oral labetalol. Conclusion: The present study indicates labetalol to be better antihypertensive in terms of control of hypertension and fetal outcome.
\end{abstract}

Keywords: Nifedipine, labetalol, PIH, preeclampsia.

Hypertensive disorder of pregnancy, one of the causes of morbidity and mortality both in mother and fetus. ${ }^{1}$ It constitutes the most widely analyzed condition as it badly affects mother and fetus. It complicates about $5-10 \%$ of all pregnancies leading to maternal morbidity and mortality. ${ }^{2}$

Hypertensive disorder of pregnancy includes preeclampsia, eclampsia, gestational hypertension, chronic hypertensive and preeclampsia superimposed on chronic hypertensive. ${ }^{3}$ Among them preeclampsia and eclampsia are the major causes of maternal and perinatal morbidity and mortality. ${ }^{1} \quad$ Pregnancy with hypertension predisposes to complications like antepartum haemorrhage (APH), disseminated intravascular coagulation (DIC), cerebral hemorrhage, hepatic failure, renal failure, HELLP syndrome, ${ }^{4}$ intrauterine growth restriction (IUGR) and intrauterine death (IUD). Preeclampsia is defined as a systolic blood pressure (SBP) $\geq 140 \mathrm{~mm}$ of $\mathrm{Hg}$ or diastolic blood pressure (DBP) $\geq 90 \mathrm{~mm}$ of $\mathrm{Hg}$ on two occasions at least four hours apart after 20 weeks of gestation in women with a previously normal blood pressure (BP) ${ }^{5}$

Selection of antihypertensive agents is the major issue concerned with preeclampsia. Labetalol, nifedipine and methyldopa are preferred choice of drugs. Our study focuses on assessment, safety and efficacy of oral labetalol and oral nifedipine and also the maternal and fetal outcome.

Methods

A prospective comparative study was carried out in obstetrics and gynaecology department BRIMS tertiary care center Bidar between June 2019 to December 2019 after taking ethical committee clearance. The efficacy of labetalol versus nifedipine in management of hypertensive disease of pregnancy was studied. A total of 60 antenatal women with gestational age between $20-40$ weeks irrespective parity and diagnosed as pregnancy induced hypertension (PIH) were

Received: $8^{\text {th }}$ July 2020, Peer review completed: $20^{\text {th }}$ August 2020, Accepted: $7^{\text {th }}$ September 2020.

Deshmukh UB, Savitha A, Tengli S. Comparative study of labetalol and nifedipine in management of hypertensive disorders of pregnancy in BRIMS tertiary care center. The New Indian Journal of OBGYN. 2021; 8(1): 117-20. 
The New Indian Journal of OBGYN. 2021 (July-December);8(1)

studied.

Inclusion criteria

1) All pregnant women with hypertension whose two blood pressure recordings are $\geq 140 / 90 \mathrm{~mm} \mathrm{Hg}$ more than 6 hours apart.

2) Pregnant women with gestational age from 20 weeks of pregnancy till term.

3) Pregnant women who gave consent.

Exclusion criteria

1) Multifetal pregnancy, eclampsia, and women with preexisting or concurrent medical disorders like diabetes mellitus, cardiac diseases, renal disease, thyrotoxicosis, hemophilia and chronic hypertension.

2) Pregnant women with IUD at presentation.

3) Pregnant women those not given consent

A total number of 60 pregnant women with PIH were studied. They were divided into two groups 30 each. Group A received labetalol and group B received nifedipine. Then the effects of labetalol and nifedipine were compared. Labetalol was started at an initial dose of $100 \mathrm{mg}$ twice daily (BD) and the dose was increased as required. Maximum dose of $200 \mathrm{mg}$ thrice daily (TDS) was given. Nifedipine was started with an initial dose of $10 \mathrm{mg} \mathrm{BD}$ and the dose was increased up to $20 \mathrm{mg}$ TDS. Patients were monitored daily for blood pressure and fetal well being.

Statistical analysis was done by using unpaired t-test for comparison with p-value $(<0.05$ $P$ value considered significant).

\section{Results}

Table-1, depicts that maximum number of patients in both groups belongs to age group of 21-25 years. Table -2, draws the inference that majority of pregnant women were primigravida about $63.30 \%$ in labetalol group and $60 \%$ in nifedipine group. Table-3, concludes that maximum patients were in term gestation age 37- 40 weeks in both the groups. Table -4 , shows comparison of mean and standard deviation (SD) of SBP, DBP and MAP between the two groups before treatment and after treatment. Before treatment the SBP, DBP and MAP are not statistically significant but after treatment the SBP, DBP and MAP are extremely significant ( $\mathrm{p}$-value $<0.0001$ ) in labetalol group. This shows significant decrease in SBP, DBP and MAP in labetalol group when compared to nifedipine.

The time required to achieve control of blood pressure in group A (labetalol) was 29.8 hours and in B (nifedipine) group was 34.4 hours ( $p$ value 0.042 ) which indicates

Table 1: Age wise distribution of cases

\begin{tabular}{lllll}
\hline \multirow{2}{*}{$\begin{array}{l}\text { Age in } \\
\text { years }\end{array}$} & \multicolumn{2}{l}{ Labetalol (Group A) } & \multicolumn{2}{l}{ Nifedipine (Group B) } \\
\cline { 2 - 5 } No. & \% & No. & \% \\
\hline Up to 20 years & 07 & 23.30 & 06 & 20.00 \\
21-25 years & 14 & 46.60 & 15 & 50.00 \\
26-30 years & 06 & 20.00 & 07 & 23.30 \\
$>$ 30 years & 03 & 10.00 & 02 & 6.60 \\
\hline Total & $\mathbf{3 0}$ & $\mathbf{1 0 0 . 0 0}$ & $\mathbf{3 0}$ & $\mathbf{1 0 0 . 0 0}$ \\
\hline
\end{tabular}

Table 2: Case distribution based on parity

\begin{tabular}{lllll}
\hline & \multicolumn{2}{l}{ Group A; Labetalol } & \multicolumn{2}{l}{ Group B; Nifedipine } \\
\cline { 2 - 5 } Gravidity & No. & \% & No. & \% \\
\hline 1 & 19 & 63.30 & 18 & 60.00 \\
2 & 07 & 23.30 & 08 & 26.60 \\
3 & 04 & 13.30 & 04 & 13.30 \\
\hline Total & $\mathbf{3 0}$ & $\mathbf{1 0 0 . 0 0}$ & $\mathbf{3 0}$ & $\mathbf{1 0 0 . 0 0}$ \\
\hline
\end{tabular}

Table 3: Case distribution based on gestational age.

\begin{tabular}{lllll} 
Gestational & \multicolumn{2}{l}{ Group A; Labetalol } & \multicolumn{2}{l}{ Group B; Nifedipine } \\
\cline { 2 - 5 } Age & No. & \% & No. & \% \\
\hline $20-24$ weeks & 00 & 00.00 & 00 & 00.00 \\
$24-27$ weeks & 04 & 13.30 & 02 & 6.60 \\
$27-30$ weeks & 05 & 16.60 & 04 & 13.30 \\
$31-34$ weeks & 05 & 16.60 & 06 & 20.00 \\
$34-37$ weeks & 07 & 23.30 & 08 & 26.60 \\
$37-40$ weeks & 09 & 30.00 & 10 & 33.30 \\
\hline Total & $\mathbf{3 0}$ & $\mathbf{1 0 0 . 0 0}$ & $\mathbf{3 0}$ & $\mathbf{1 0 0 . 0 0}$
\end{tabular}

BP, DBP and MAP among the two groups

\begin{tabular}{lllllll}
\multicolumn{2}{l}{ Table 4: Comparison of mean SBP, DBP and MAP among the two groups } \\
\hline \multicolumn{2}{l}{ Parameters } & $\begin{array}{l}\text { Labetalol } \\
\text { (Mean, SD) }\end{array}$ & $\begin{array}{l}\text { Nifedipine } \\
\text { (Mean, SD) }\end{array}$ & t-value & df & P-value \\
\hline SBP & Before treatment & $153.2,5.455$ & $152.2,6.72$ & 0.6328 & 58 & $0.5293 \mathrm{NS}$ \\
& After treatment & $124.2,4.142$ & $138.4,4.715$ & 12.392 & 58 & $<0.0001 \mathrm{~S}$ \\
DBP & Before treatment & $102.4,5.425$ & $104.8,6.22$ & 1.592 & 58 & 0.1167 \\
& After treatment & $90,3.687$ & $99.8,1.399$ & 13.6115 & 58 & $<0.0001 \mathrm{ES}$ \\
MAP & Before treatment & $118.82,5.457$ & $120.59,4.323$ & 1.3925 & 58 & $0.1691 \mathrm{NS}$ \\
& After treatment & $101.39,3.451$ & $112.67,2.300$ & 14.897 & 58 & $<0.0001 \mathrm{ES}$ \\
\hline
\end{tabular}
SBP - Systolic blood pressure; DBP - Diastolic blood pressure; MAP - Mean arterial pressure; NS - Not significant; $\mathrm{S}$ - Significant; ES - Extremely significant.

labetalol group had control of blood pressure earlier than nifedipine group (table 5). Maintenance of control of blood pressure was more effective in labetalol group for 72 hours from the starting dose, than nifedipine group. Group A, labetalol received $100 \mathrm{mg}$ BD starting dose and was increased to $200 \mathrm{mg}$ TDS and requirement of additional oral antihypertensive was seen in only 2 women. Whereas group $\mathrm{B}$, nifedipine received $10 \mathrm{mg} \mathrm{BD}$ as starting dose and was

\begin{tabular}{lllc} 
Table 5: Primary outcome (efficacy) & & & \\
\hline Parameters & $\begin{array}{l}\text { Labetalol } \\
(\mathbf{N}=\mathbf{3 0})\end{array}$ & $\begin{array}{l}\text { Nifedipine } \\
(\mathbf{N = 3 0 )}\end{array}$ & P - value \\
\hline $\begin{array}{l}\text { Time required to control blood pressure } \\
\text { (in hours) }\end{array}$ & 29.8 & 34.4 & 0.042 \\
\hline $\begin{array}{l}\text { Sustained blood pressure control for 3 } \\
\text { days (in \%) }\end{array}$ & 52.0 & 37.0 & 0.001 \\
\hline
\end{tabular}


The New Indian Journal of OBGYN. 2021 (July-December);8(1)

\begin{tabular}{|c|c|c|}
\hline \multicolumn{3}{|l|}{ Parameters } \\
\hline \multicolumn{3}{|c|}{$\begin{array}{l}\text { Additional oral hypertensive required for control BP } \\
\text { Additional intravenous (IV) hypertensive required } \\
\text { Hospital stay (in days) }\end{array}$} \\
\hline \multirow{5}{*}{\multicolumn{3}{|c|}{$\begin{array}{l}\text { increased to } 20 \mathrm{mg} \text { TDS and requirement of additional } \\
\text { antihypertensive drug was noted in } 3 \text { women. Group A } \\
\text { (labetalol) required additional antihypertensive drug } \\
\text { nifedipine to control blood pressure among } 2 \text { patients. Group } \\
\mathrm{B} \text { (nifedipine) required labetalol as an additional antihyper- } \\
\text { tensive to control blood pressure among } 3 \text { patients. } \\
\text { Intravenous (IV) antihypertensive was given to control acute } \\
\text { severe hypertension } 1 \text { or } 2 \text { doses in } 6 \text { patients in labetalol } \\
\text { group and } 8 \text { patients in nifedipine group. The average } \\
\text { hospital stay was around } 3 \text { days in labetalol group and } 4 \text { days } \\
\text { in nifedipine group respectively (table } 6 \text { ). } \\
\text { Table 7: Case distribution based on maternal complications and drug } \\
\text { side effects }\end{array}$}} \\
\hline & & \\
\hline & & \\
\hline & & \\
\hline & & \\
\hline Complications & $\begin{array}{l}\text { Labetalol } \\
\text { (Group A) }\end{array}$ & $\begin{array}{l}\text { Nifedipine } \\
\text { (Group B) }\end{array}$ \\
\hline Severe hypertension & & 3 \\
\hline Eclampsia & & \\
\hline & & \\
\hline ion & & 2 \\
\hline Palpitation & & \\
\hline & & \\
\hline Flushing & & 1 \\
\hline
\end{tabular}

\begin{tabular}{lllll}
\multicolumn{2}{l}{ Table 8: Cases according to fetal outcome } \\
\hline $\begin{array}{l}\text { Fetal } \\
\text { outcome }\end{array}$ & \multicolumn{2}{l}{ Group A; Labetalol } & \multicolumn{2}{l}{ Group B; Nifedipine } \\
No. & \% & No. & \% \\
\hline Preterm & 05 & 16.67 & 07 & 23.33 \\
Term & 25 & 83.33 & 23 & 76.67 \\
\hline Mean & 37.23 & & 36.76 & \\
SD & 2.124 & & 2.431 & \\
\hline
\end{tabular}

\begin{tabular}{lllll}
\multicolumn{5}{l}{ Table 9: Case distribution according to birth weight. } \\
\hline $\begin{array}{l}\text { Fetal outcome } \\
\text { birth weight }\end{array}$ & \multicolumn{2}{l}{ Group A; Labetalol } & \multicolumn{2}{l}{ Group B; Nifedipine } \\
No. & \% & No. & \% \\
\hline$<2.5 \mathrm{~kg}$ & 04 & 13.40 & 06 & 20.00 \\
$\geq 2.5 \mathrm{~kg}$ & 26 & 86.60 & 24 & 80.00 \\
\hline Mean & 2.646 & & 2.586 & \\
SD & 0.256 & & 0.2929 & \\
\hline
\end{tabular}

Nifedipine showed maximum complications of severe hypertension, eclampsia and abruption. It was also noted that headache, palpitation and hypotension were seen in nifedipine group (table 7). No statistical difference in comparing fetal outcome in the two groups ( $\mathrm{p}$ value $>$ $0.4284, t=0.7974)$. This show slightly lower incidence of preterm labour in labetalol group (table 8 ). There was no significance on comparing birth weight $(\mathrm{p}>0.4017, \mathrm{t}=$ 0.8448) (table 9).

\begin{tabular}{lll} 
Labetalol (N=30) & Nifedipine $(\mathbf{N}=\mathbf{3 0})$ & $\mathbf{P}-$ value \\
\hline 2 & 3 & 0.733 \\
6 & 8 & 0.79 \\
3 & 4 & 0.899 \\
\hline
\end{tabular}

Discussion

The maximum number of patients in labetalol and nifedipine group belong to $21-25$ years of age and amongst most of them belonged to primigravida, which was in accordance to Shekhar et al (2013) $)^{6}$ and Hangarga et al (2016). ${ }^{7}$ Most of the women were between gestational age of 34-40 weeks, which was found similar to Hangarga et al study. In Labetalol group the fall in mean SBP was $29 \mathrm{~mm}$ of $\mathrm{Hg}$ (153.2 to 124.2) and the fall in mean DBP was 12.9 (102.4 to 90.00) which was statistically significant corresponding to Michael et al study ${ }^{8}$ and Stott et al ${ }^{9}$. In nifedipine group the mean fall in SBP was $13.8 \mathrm{~mm}$ of $\mathrm{Hg}$ (152.2 to 138.4) and DBP is 5 (104.8 to 99.8 ) which was not that statistically significant. So overall, labetalol group showed better control of BP both SBP and DBP when compare to nifedipine. The commonest side effects were tachycardia, postural hypotension, and occipital headache seen more in nifedipine group. Fetal outcome was better with both the group which was statistically not that significant.

Previous trials conducted on safety and efficacy of labetalol (oral), oral nifedipine, IV labetalol, hydralazine and methyldopa were found to be effective antihypertensive agents ${ }^{10,11}$. Veena et $\mathrm{al}^{12}$, Vermillion et $\mathrm{al}^{13}$, Raheem A et a $1^{10}$ compare oral nifedipine to IV labetalol in management of hypertension of pregnancy. In our study, labetalol achieved significantly earlier and sustained control blood pressure in comparison to nifedipine, which was in accordance to study conducted by Sharma et al (2017) ${ }^{14}$.

Previously studies reported headache palpitation and hypotension as common side effects with use of nifedipine when compare to labetalol and these observations were also noted in our study ${ }^{13}$. The need for an additional antihypertensive was nearly seen in both groups ${ }^{14}$. Nita $\mathrm{K}$ Patel et $\mathrm{al}^{15}$ conducted a prospective study to evaluate the effectiveness and safety of nifedipine, methyldopa and labetalol in PIH and concluded that labetalol was more effective than nifedipine and methyldopa. Our data supports the recent guidelines and expert opinion that labetalol is the suitable first line antihypertensive for hypertensive diseases and emergencies in pregnancy. 
The New Indian Journal of OBGYN. 2021 (July-December);8(1)

\section{Conclusion}

We observed in our study that oral labetalol is more efficacious than oral nifedipine. In our prospective study oral labetalol was better in terms of controlling BP and fetal outcome.

\section{Conflict of interest: None. Disclaimer: Nil.}

\section{References}

1. WHO. WHO recommendations for Prevention and Treatment of Pre-eclampsia and eclampsia. WHO Handbook for guideline development. Geneva: World Health Organization; 2010.

2. Sibai BM, Grossman HG. Effects of diuretics on plasma volume in pregnancies with long term hypertension. Am J Obstetr Gynecol. 1984;150: 831-5.

3. ACOG. Classification of Hypertensive Disorders. Washington: ACOG; 2013.

4. Queensland Clinical Guidelines. Hypertensive disorders of pregnancy. Herston Qld: Queensland Maternity and Neonatal Clinical Guideline; 2010.

5. ACOG. Preeclampsia: Hypertension in pregnancy report of the American college of obstetricians and gynecologists' task force on hypertension in pregnancy. ACOG 2013;122:1122-31.

6. Shekhar S, Sharma C, Thakur S, Verma S. Oral Nifedipine or Intravenous Labetalol for hypertensive emergency in pregnancy: a randomized controlled trial. Obstetrics \& Gynecology. 2013; 122(5):1057-63.

7. Hangarga US, Rita D, Harshitha K. Comparative study of labetalol and nifedipine in management of hypertensive disorders in pregnancy. International Journal Reproduction Contraception, Obstetrics Gynecology. 2017; 6:194-7.

8. Michael CA. The evaluation of labetalol in the treatment of hypertension complicating pregnancy. British journal of clinical pharmacology. 1982; 1:13(S1).
9. Stott D, Bolten M, Salman M, Paraschiv D, Douiri A, Kametas NA. A prediction model for the response to oral labetalol for the treatment of antenatal hypertension. Journal of human hypertension, 2016; 31(2): 126-31.

10. Raheem A, Saaid R, Omar S, Tan PC. Oral nifedipine versus intravenous labetolol for acute blood pressure control in hypertensive emergencies of pregnancy: a randomized trial. BJOG. 2012;119(1):78-85.

11. Cairns AE, Pealing L, Duffy JMN, Roberts N, Tucker $\mathrm{KL}$, Leason $\mathrm{P}$, et al. Post-partum management of hypertensive disorders of pregnancy: a systematic review. BMJS Open. 2017;7(11):e18696.

12. Veena P, Perivela L, Raghavan SS. Furosemide in Postpartum management of severe pre-eclampsia: a randomized controlled trial. Hyperten Pregnancy. 2017;36(1):84-9.

13. Vermillion ST, Scardo JA, Newmann RB, Chauhan SP A randomized double blind trial of oral nifedipine and intravenous labetolol in hypertensive emergencies of pregnancy. Am J Obstet Gynaecol. 1999;181(4):858-61.

14. Sharma KJ, Greene N, Kilpatrick SJ. Oral Labetolol compared to oral nifedipine for post-partum hypertension. A randomized controlled trial. Hyperten Pregnancy. 2017; 36(1): 44-7.

15. Patel NK, Gadhavi M, Gorasia D, Pandya MR. Comparative evaluation of antihypertensive drugs in the management of pregnancy-induced hypertension. Int $\mathrm{J}$ Basic Clin Pharmacol. 2012; 1:174-7.

\footnotetext{
Uma B Deshmukh ${ }^{1}$, Savitha $A^{2}$, Sangeeta Tengli ${ }^{3}$

${ }^{1}$ Associate Professor, Department of OBG, BRIMS, Bidar, Karnataka, India; ${ }^{2}$ Assistant Professor, Department of Pharmacology, BRIMS, Bidar, Karnataka, India; ${ }^{3}$ Assistant Professor, Department of OBG, BRIMS, Bidar, Karnataka, India.
} 